\title{
Production Processes Choices
}

\section{The Role of Proprietary Processes}

One of the questions pursued in researching the SME cohort in this study centered around the arrangements of the factory floor. Given that these SMEs were exporters, manufacturing or assembling products and competing with usually larger companies across the globe, the question about how a smaller competitor can compete on a smaller manufacturing base is, of course, a central one. In many cases, it was not only possible to discuss this question with company management, but also to walk the floor and get a visual impression of the environment. As it turns out, it is the proprietary processes which are of crucial importance to many companies and contribute substantially to a company's competitiveness. Again, there were different approaches about how best to arrive at this special position. For technologically and engineering-driven companies, it should not come as a surprise that sometimes ingenious solutions were adopted. Some of those solutions are described below.

\section{Designing Proprietary Production Lines}

First, there are those companies that adapted off-the-shelf production equipment into a proprietary production line that move beyond the capabilities of the standard supplied equipment. ${ }^{1}$

- Ricola acquired its production equipment from external suppliers, particularly for the extraction method applied and then tied each step into a continuous flow. Processes were proprietary and developed internally. This meant that any potential competitor acquiring the same equipment from an external supplier would still not be able to arrive at the same end results.

\footnotetext{
${ }^{1}$ Summaries based upon company profiles. 
- Fraisa production processes were becoming increasingly automated. Production lines were equipped with a combination of purchased machinery, developed with partners and suppliers, and combined into a unique production line. None of the installations could be bought off the shelf.

- Kuhn Rikon's plant in Rikon focused on its long-established cookware business. This product line, accounting for about one-third of total sales, was entirely produced in Rikon using a modern, custom-designed, and robot-enhanced production line.

- Caran d'Ache likened its manufacturing process for graphite, the "dough" for pencil cores, to "cooking, similar to pasta or baking bread." It involved 35 different steps and the company owned about 800 different pieces of manufacturing equipment, many designed internally.

- Oetiker did not see itself as the typical exporter with a Swiss base. Production activity in Horgen focused on core tools needed for the 12 foreign production operations. Key tools were required for the stamping operations, assembly tools, as well as for critical components in production machinery located at the various foreign production operations. Production equipment was proprietary and engineered, or adapted, by Oetiker for its own needs.

- Medartis employed titanium exclusively as the material for its implants, posing some special production challenges. Medartis machined its screws (not milled or cut with water jets). The company developed its production processes to the point where machining time in titanium was as short as it was for stainless steel screws or plates, leading to important savings through efficiency. Machinery was first sourced from Switzerland, but the company later switched to a German supplier who offered better service, including even on Sundays as is required when the company moved to a $24 / 7$ operation.

The story that surfaced at Sefar was more involved and gives an idea about how a proprietary production line, one that operated with external equipment, evolves in order to make it difficult for any competitor to duplicate. Over the more than 150 years of the company's history, there is a consistent pattern of production process innovations and improvements, beginning even in the first phase, when processes from standard hand weaving looms were replaced by modern mechanical weaving looms situated in a plant. The process of improving Sefar's weaving plant, however, did not stop there and the company management went to great lengths to protect its process knowledge.

Sefar typically bought standard weaving machines as developed by weaving machine builders. Then, Sefar further optimized the machines with parts from local manufacturers so that, in the end, the equipment was 10 percent more efficient and produced better quality than when originally acquired. Sefar considered production as one of the company's success factors. It did not patent its improved weaving technologies, instead it tried to protect its process innovations by keeping them secret. A weaving machine manufacturer was never 
allowed to enter Sefar's machine hall. When Sefar bought a new machine, the manufacturer had to unload it in front of the factory. ${ }^{2}$

SMEs, as creators of superior products, are well aware that copycats might always duplicate their visible features. However, if there is something proprietary in the production process and one that is closely tied to the end result, the company may be able to prevent copying. This required companies to become skilled in the production process design and, in a manner of speaking, invade the territory of their machine suppliers.

\section{Building Custom Equipment}

In some cases, companies went beyond stitching together purchased equipment and built their own equipment. This was a step beyond, toward proprietary production lines, and further protecting the production processes by making the equipment unavailable in the open market. Bachem initially produced peptides with equipment acquired from specialized, open-market suppliers. Over time, the company developed its own manufacturing processes based upon in-house intellectual property (IP).

Geistlich, also active in the life sciences field, found that it had to literally invent the entire production process.

At Geistlich, production processes for biomaterials differed radically from the previous industrial production model and had to be developed. Careful selection of bovine bones was required, and bone or collagen sourced exclusively from monitored establishments. Highly effective cleaning and purification processes were installed. The production processes were subject to regular inspections by various independent institutions and government authorities. End products were subjected to meticulous sterilization in sterile pressure chambers, not only for manufacturing but also for packaging. All products were subject to individual manual quality control at the Swiss plant. The Geistlich manufacturing process was enhanced through complete in-house integration of all important process steps, as well as the accumulation of a large number of patents that were granted on its original products. The combination of these approaches made it very difficult for potential competitors to enter this space and was a prime reason why Geistlich could achieve dominance in this field. ${ }^{3}$

Although Geistlich developed its production process by integrating each step, the company still had a number of product-related patents that provided additional protection from competition.

That a proprietary process can work even when patents have expired is documented by the experience of Rüeger, as a small player competing globally with its engineered temperature probes.

Once the patent protection expired, Rüeger did not experience any duplications or imitations. The reason had to do with the difficult manufacturing process required for its

\footnotetext{
${ }^{2}$ Adapted from Sefar company profile.

${ }^{3}$ Adapted from Geistlich company profile.
} 
temperature probes. Rüeger, over the years, developed a unique manufacturing process based upon its own machinery and equipment. This equipment was not available on the open market as it had been custom built by Rüeger. As a result, the manufacturing process became a significant barrier to entry, which protected Rüeger beyond the patent protection time. The know-how required for the production process meant that the company produced all sensitive components in its plant in Switzerland and sent them to other locations for final assembly. ${ }^{4}$

For maxon, producing millions of high-performing electrical motors, a core aspect of production was its winding process for rotor manufacturing.

Winding machines were developed and made in maxon's Swiss plant with a team of dedicated production engineers. The process was patented and the equipment was not available on the open market. The equipment was constantly modified and improved, reaching Industry 4.0 standard. Over time, the winding time of rotors was steadily improved from initially ten minutes, down to five minutes, later to one minute, and finally into the 12 second range with the latest generation of equipment. ${ }^{5}$

Developing winding machines internally meant that such equipment was not available on the open market, providing a significant protection against imitators or potential competitors.

Both Oetiker and maxon were also functioning as their own production line builders, combining proprietary production equipment with self-developed production lines at their head office plant in Switzerland and then shipping them to overseas production locations. LEM pursued a similar strategy in developing, piloting and engineering their production lines in Geneva and then making them available for their international production sites.

\section{Installing Automation and Robotization}

Many of the SMEs found that they needed to move increasingly into automation and robotization of their operations. The typical rationale was to escape the high labor costs incurred by the Swiss-based labor force. The adoption of process automation was usually undertaken step-by-step, rather than in one single, large fully automated production line. These are a few examples of this process.

- In 2017, Ricola produced 7 billion individual drops a year. The processes were highly automated.

- The production processes at Fraisa were becoming increasingly automated with equipment running 24/7, as well as on weekends, unattended.

- Sylvac's Malleray site in the Jura focused on the hand-held measurement tools. Given that the company worked in small batches of lot sizes of 20 units, the

\footnotetext{
${ }^{4}$ Adapted from Rüeger company profile.

${ }^{5}$ Adapted from maxon company profile.
} 
introduction of pick and assembly robots was intended to allow for output growth with stable staffing levels. Large assembly stations allowed for flexibility.

In several companies, the latest technologies, such as Internet of Things (IoT) have become commonplace, allowing companies to move into two- or three-shift production modes, while restricting the staffing to just one shift, work through weekends.

- At Medartis, a crew of about 75 was responsible to produce the entire Medartis portfolio on fully automated and robot-enhanced lines. The company operated on a 24/7 model with three shifts, with only one of those shifts being manned. IoT was implemented throughout. All relevant production and process knowledge was owned by Medartis.

- Felco operated an integrated production where every major step was brought in-house and all production was taking place under one roof, with the exception of its aluminum forged handles which were supplied by a separate subsidiary, which Felco also owned. Considerable investment was made into manufacturing automation across all production steps for parts manufacturing and, recently, even for some assembly steps. Only the final inspection remained a manual operation. Felco moved toward implementing Industry 4.0, providing regular status of all of its production machinery to the smart phones of supervisors. Applying the Five $S$ methodology and SMED approach, it practiced TPM. The goal of all of this was to increase output while keeping its manufacturing staff at the same level.

How challenging it can be to move from old production methodologies to modern, automated ones, in addition to how to overcome the challenge of finding the best equipment suppliers, is demonstrated by Filtrox, producer of depth filters. Filtrox exemplifies how a company can, in a step-by-step process, move from mostly manually operated processes to automated ones and thus remain competitive from a cost point of view. The company management made sure that its manufacturing equipment would not be made available to competitors.

The basic method for the production of filter sheets has not changed over the last 80 years and was similar to the production of paper and cardboard. At Filtrox, this process was originally in the form of batch production. However, in the 1940s, Filtrox introduced a mechanical production process, using a second-hand machine from a paper manufacturer, which had to be converted to produce filter sheets. The wet production plant was then continuously developed further in an evolutionary process.

When the demand for filter sheets grew in the 1960s, Filtrox substantially increased production capacity, first by installing an enlarged sheet machine and, in 1972, expanding the sheet production line by enlarging the entire manufacturing plant. The new production line had a length of 72 meters and could produce six meters per minute. Subsequently, the production line was automated and improved considerably. In 2018, the entire line, the backbone of the whole company, could be run by a mere two people.

For Filtrox, it had always been difficult to find the right suppliers, because there were no standard machines for depth filter production. Furnace manufacturers and paper machine manufacturers were approached, and together with them, specific solutions for producing depth filters were developed. Frequently, the manufacturers had to sign a confidentiality and 
exclusivity agreement preventing them from selling the developed solutions to Filtrox competitors. Not all manufacturers were willing to develop new solutions together with Filtrox instead of selling their own standard machines; it was typically niche players who became involved. ${ }^{6}$

Automating production processes allowed SMEs to remain cost-competitive. However, this could only be a sustainable strategy if the advanced engineering that went into these automation projects remained proprietary. At this moment, automation served the defense of cost competitiveness and allowed companies to grow production volume with a stable workforce.

\section{Capitalizing on Long-Term Improvements}

Experts have also observed that major competitive advantage comes from production or automation processes typically accrued from improvements that have taken place over an extended period of time and are based on extensive experience. Such improvements are not mere productivity gains based upon superior engineering but skill-based improvements that are extremely difficult to duplicate for outsiders. These long-term improvements, which subsequently become part of a company's manufacturing know-how, were observed at several of the researched companies, such as maxon, Caran d'Ache and Rüeger.

Open Access This chapter is licensed under the terms of the Creative Commons Attribution 4.0 International License (http://creativecommons.org/licenses/by/4.0/), which permits use, sharing, adaptation, distribution and reproduction in any medium or format, as long as you give appropriate credit to the original author(s) and the source, provide a link to the Creative Commons license and indicate if changes were made.

The images or other third party material in this chapter are included in the chapter's Creative Commons license, unless indicated otherwise in a credit line to the material. If material is not included in the chapter's Creative Commons license and your intended use is not permitted by statutory regulation or exceeds the permitted use, you will need to obtain permission directly from the copyright holder.

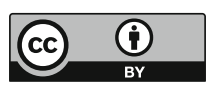

\footnotetext{
${ }^{6}$ Adapted from Filtrox company profile.
} 